\title{
Integração interna para a Integração da Cadeia de Suprimentos: um estudo multicaso
}

\author{
Internal integration for Supply Chain Integration: \\ a multicase study
}

Andréia de Abreu Siqueira ${ }^{1}$

Rosane Lúcia Chicarelli Alcântara ${ }^{2}$
${ }^{1}$ Doutora em Engenharia de Produção Docente do curso de Gestão Empresarial da Fatec Garça - Garça/SP, Brasil. andreia.abreu@fatec.sp.gov.br

2 Doutora em Administração Docente do Programa de Pós-Graduação em Engenharia de Produção da UFSCar - São Carlos/SP,
Resumo

Este artigo tem como propósito investigar a integração interna para a execução das atividades e processos de negócio da Gestão da Cadeia de Suprimentos e os efeitos gerados na Integração da Cadeia de Suprimentos. Esse enfoque de pesquisa se justifica pelo fato do crescente reconhecimento do papel da integração interna para a efetivação da Integração da Cadeia de Suprimentos. Além da revisão da literatura, realizou-se uma investigação empírica em seis empresas nacionais representativas nos seus setores de atuação. Os dados coletados foram analisados e codificados com o uso da técnica de Análise de Conteúdo. Os resultados apontaram que, de fato, a integração interna exerce um papel crucial para a efetivação dos princípios e práticas de GCS, cujos efeitos geram benefícios e melhorias tanto internamente às empresas como na integração externa com os demais elos das cadeias de suprimentos nas quais atuam. Há, portanto, uma melhoria nas ações de Integração da Cadeia de Suprimentos.

Palavras-chave: Gestão da Cadeia de Suprimentos. Integração da Cadeia de Suprimentos. Integração Interna. Estudo Multicaso.

\section{Abstract}

This paper aims to investigate internal integration for the execution of Supply Chain Management business activities and processes and the effects generated in Supply Chain Integration. This research focus is justified by the growing recognition of the role of internal integration for the success of Supply Chain Integration. In addition to the literature review, an empirical investigation was carried out on six representative national companies in their sectors of activity. The data were analyzed and coded using the Content Analysis method. The results demonstrated that, in fact, internal integration plays a crucial role in the implementation of the principles and practices of SCM, whose effects generate benefits and improvements both internally to companies and externally with the partnersof the supply chains in which they operate. Therefore, there is a better qualification for the Supply Chain Integration actions.

Key-words: Supply Chain Management. Supply Chain Integration. Internal Integration. Multicase Study. 
1 Introdução

Apesar dos benefícios a serem obtidos com a implantação dos princípios e práticas de Gestão da Cadeia de Suprimentos (GCS) amplamente mencionadas pela literatura, na realidade poucas empresas têm de fato conseguido obtê-los, especialmente no que diz respeito às iniciativas de Integração da Cadeia de Suprimentos (Fawcett, Mccarter, Fawcett, Webb, \& Magnan, 2015; Zhao, Feng, \& Wang, 2015). São três as possíveis razões para tanto: (i) a dificuldade em estabelecer relações de cooperação e colaboração com os atores à montante e à jusante da cadeia de suprimentos, envolvendo-os nas decisões estratégicas (Koufteros, Vonderembse, \& Jayaram, 2005), (ii) a dificuldade de integração interna entre as áreas funcionais com atribuição de atividades diretamente relacionadas com a GCS (Richey, Chen, Upreti, Fawcett, \& Adams, 2009) e (iii) a desatenção e/ou falta de conhecimento, por parte das empresas, de que a concepção de GCS envolve tanto a extensão de suas fronteiras por meio das relações de integração externa quanto das relações interfuncionais (Basnet, 2013). Observa-se que a terceira razão comporta as duas razões anteriores.

De fato, as definições de GCS trazem essa concepção. Entre elas, destaca-se a apresentada por Mentzer et al. (2001, p.18):

Coordenação sistemática e estratégica das funções gerenciais tradicionais e das táticas entre elas dentro de uma empresa e, entre empresas, dentro da cadeia de suprimentos, para melhoria do desempenho de longo prazo das empresas separadamente e da cadeia como um todo.

Há também a desenvolvida pelos membros da Global Supply Chain Forum - GSCF (Lambert, 2008, p.2): "a gestão da cadeia de suprimentos é a integração dos processos-chave de negócio desde o usuário final até os fornecedores originais a fim de prover produtos, serviços e informações que agregam valor aos clientes e outras partes interessadas". Consequentemente, a compreensão de Integração da Cadeia de Suprimentos é subsidiada por tal concepção, sendo definida como as interfaces intra e interorganizacionais que facilitam a coordenação e a eficácia dos fluxos de informação, material, dinheiro e decisões destinadas a criar valor para o cliente e reduzir os custos globais (Schoenhrrer \& Swink, 2012).

Embora no contexto de cadeia de suprimentos o termo "integração" seja frequentemente mencionado de maneira genérica, a definição das fronteiras entre a integração interna e externa é essencial, principalmente por desempenharem papéis complementares (Barrat \& Barrat, 2011). Enquanto a integração interna reconhece que os departamentos e funções dentro de uma empresa devem funcionar como parte de um processo integrado, a integração externa reconhece a importância de estabelecer relações estreitas e interativas com clientes e fornecedores (Ralston, Blackhurst, Cantor, \& Crum, 2015).

No entanto, o papel da integração interna para a efetivação da Integração da Cadeia de Suprimentos vem ganhando crescente destaque na literatura especializada (Kamal \& Irani, 2014) sendo inclusive reconhecida por diferentes autores como um pré-requisito, ou ainda um primeiro estágio, para a integração plena de uma empresa em sua cadeia de suprimentos (por exemplo - Jin, Fawcett, \& Fawcett, 2013; Horn, Scheffler, \& Schiele, 2014; Yunus \& Tadisina, 2016). Conforme ressaltam Kotzab, Teller, Grant e Sparks (2011, p.241) “é preciso deixar a casa 
em ordem" antes de planejar ou intensificar as relações de parcerias entre os membros de uma cadeia de suprimentos.

Este artigo se situa nesse recorte de discussão - a dimensão intraorganizacional - tendo como propósito investigar a integração interna para a execução das atividades e processos de negócio da GCS e os efeitos gerados na Integração da Cadeia de Suprimentos. Para tanto, além da revisão da literatura, foi realizada uma investigação empírica, juntamente com gestores de cadeia de suprimentos, em seis empresas nacionais representativas nos seus setores de atuação.

Os resultados desta pesquisa apresentam uma importante contribuição para a área da Gestão de Operações uma vez que busca responder ao chamado da necessidade de uma maior conscientização da relevância da integração interna para a efetividade das ações de Integração da Cadeia de Suprimentos. Conforme ressaltam Wong, Wong e Boon-Itt (2013, p.569), "sem a integração interna, os esforços de integração externa bateriam em uma parede intransponível na interface entre duas empresas". Tal conscientização não deve ocorrer somente no âmbito acadêmico, mas principalmente no âmbito das organizações, por parte dos gestores de cadeia de suprimentos ou dos gestores de áreas funcionais com atividades relacionadas com a GCS.

O artigo está estruturado em cinco seções, a contar desta introdução. A seção 2 é dedicada à fundamentação teórica. Os procedimentos metodológicos para a pesquisa de campo estão descritos na seção 3, seguidos pela apresentação e análise dos resultados (seção 4). A seção 5 dedica-se às considerações finais.

\section{Fundamentação teórica \\ 2.1 Integração interna}

Em essência, a integração interna se refere ao compartilhamento de conhecimento e informação dentro e entre as áreas funcionais, bem como entre essas e as de seus parceiros (Braganza, 2002). Desse modo, a integração reflete quão harmoniosamente os diferentes departamentos de uma organização trabalham em conjunto e quão firmemente suas atividades são coordenadas (Barki \& Pinsonneault, 2005).

Kahn e Mentzer (1996, p.9) a definem como sendo "[...] um processo de interação e colaboração interdepartamental que reúne departamentos em uma organização coesa". Interação se refere ao desenvolvimento de atividades formais e coordenadas entre os departamentos, ao passo que a colaboração se refere ao desenvolvimento de atividades não estruturadas, de natureza social e afetiva, implicando a existência de relacionamentos próximos e coesos. O Quadro 1 apresenta maiores detalhes sobre a caracterização das dimensões interação e colaboração. 
Quadro 1 - Caracterização das dimensões de integração interfuncional

\begin{tabular}{|c|c|c|c|}
\hline & Natureza & Fatores condicionantes & Recursos utilizados \\
\hline 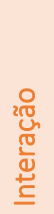 & Formal & $\begin{array}{l}\text { - estrutura organizacional: atividades e } \\
\text { hierarquia formalizadas } \\
\text { - comunicação formal } \\
\text { - adesão às decisões tomadas pela alta } \\
\text { administração }\end{array}$ & $\begin{array}{l}\text { - reuniões formais } \\
\text { - formação de comitês } \\
\text { - utilização de documentos padronizados } \\
\text { (memorandos, relatórios) } \\
\text { - troca de mensagens eletrônicas }\end{array}$ \\
\hline 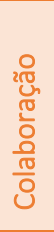 & Informal & $\begin{array}{l}\text { - confiança e comprometimento } \\
\text { - comportamento colaborativo } \\
\text { - cooperação (ao invés de competição) } \\
\text { - relacionamentos informais } \\
\text { - traços afetivos voluntários }\end{array}$ & $\begin{array}{l}\text { - metas e objetivos conjuntos } \\
\text { - trabalho conjunto } \\
\text { - compartilhamento de informação e } \\
\text { conhecimento } \\
\text { - ações voluntárias para a resolução de } \\
\text { problemas }\end{array}$ \\
\hline
\end{tabular}

Fonte: Adaptado de Kahn e Mentzer (1996).

Já no contexto da GCS, Flynn, Huo e Zhao (2010, p.59), a definem como “[...] o grau no qual um fabricante estrutura suas próprias estratégias organizacionais, práticas e processos em colaboração, sincroniza processos, a fim de cumprir os requisitos de seus clientes e interagir de forma eficiente com seus fornecedores". São inúmeros os benefícios advindos da integração interna apontados pela literatura, inclusive para a GCS, tais como: (i) redução do ciclo de pedidos, (ii) melhoria na comunicação, (iii) projetos de desenvolvimentos de novos produtos mais rápidos e precisos, (iv) aumento da sinergia e redução de erros, (v) tomada de decisão mais acertadas, (vi) melhores níveis de serviços ao consumidor, (vii) maior nível de coordenação entre as diferentes atividades funcionais, (viii) maior envolvimento dos profissionais e (ix) melhoria dos resultados funcionais (Koufteros et al., 2005; Schoenherr \& Swink, 2012; Basnet, 2013).

\subsection{Integração interna para a GCS}

A noção de cadeia de suprimentos também se aplica ao contexto interno das empresas. Para Chopra e Meindl (2012), dentro de cada empresa a cadeia de suprimentos inclui todas as funções envolvidas no pedido do cliente, como desenvolvimento de novos produtos, marketing, operações, distribuição, finanças, entre outras. O nível de cadeia interna também é previsto na configuração proposta por Chen e Paulraj (2004), conforme representada na Figura 1. No caso, as interações para a troca de materiais, informações e serviços devem ocorrer entre os as áreas funcionais de compras, produção e distribuição.

Figura 1 - Representação de uma cadeia de suprimentos

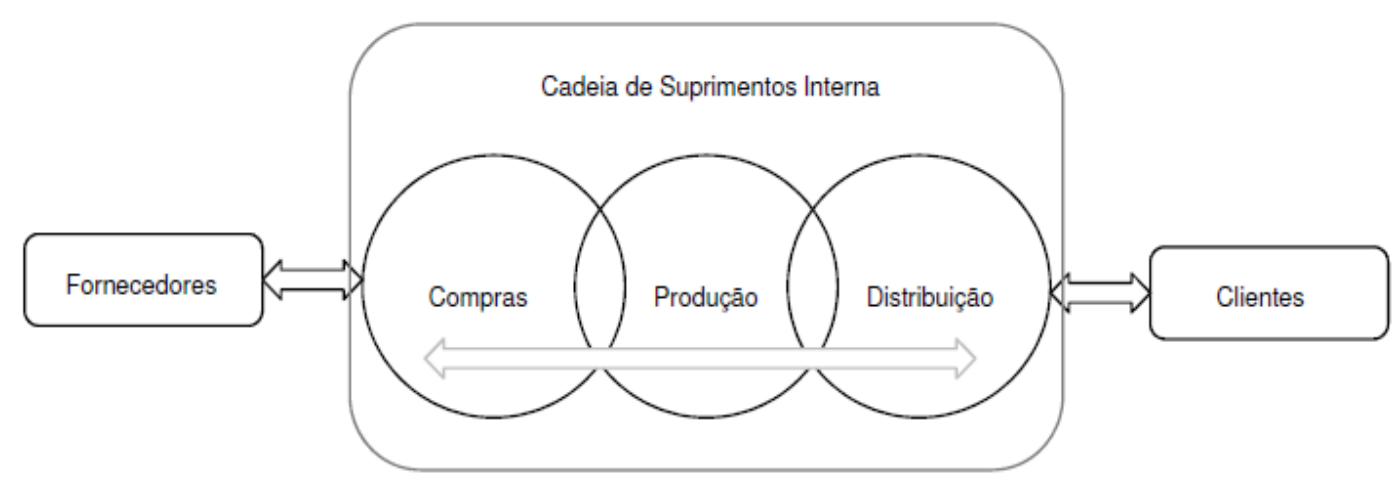

Fonte: Chen e Paulraj (2004, p.132) 
Diferentes áreas funcionais estão envolvidas com a GCS (Barrat \& Barrat, 2011). Para Pires (2010), a função abrange diversas áreas funcionais tradicionais das empresas industriais e seus profissionais em pelo menos quatro vertentes: (i) como uma expansão da Gestão da Produção, (ii) como uma expansão da Logística, (iii) como uma expansão do Marketing e (iv) como uma expansão de Compras. Visão semelhante é apresentada por Fawcett e Waller (2013) ao caracterizar as contribuições das áreas funcionais de logística, produção e compras nas relações com a cadeia de suprimentos a fim de atender as dimensões de valor para o cliente, conforme exposto no Quadro

2.

Quadro 2 - Contribuição das áreas funcionais para a GCS

\begin{tabular}{|c|c|c|c|}
\hline $\begin{array}{c}\text { Dimensão de } \\
\text { valor }\end{array}$ & Contribuição da logística & Contribuição da produção & Contribuição de compras \\
\hline Custo & $\begin{array}{l}\text { Reduzindo os custos de logística, } \\
\text { uma empresa pode diminuir o } \\
\text { custo total e ser mais competitiva } \\
\text { nos seus mercados. }\end{array}$ & $\begin{array}{l}\text { Buscando atender as metas de } \\
\text { custos via crescimento da } \\
\text { produtividade e aprendizagem } \\
\text { constante. }\end{array}$ & $\begin{array}{l}\text { Trabalhando em conjunto com } \\
\text { os fornecedores para reduzir os } \\
\text { custos da cadeia de suprimentos. }\end{array}$ \\
\hline Qualidade & $\begin{array}{l}\text { Evitando danificar os produtos } \\
\text { durante o transporte e ofertando } \\
\text { serviços de entrega exclusivos e } \\
\text { adaptados aos clientes. }\end{array}$ & $\begin{array}{l}\text { Padrões de qualidade definidos } \\
\text { devem ser introduzidos na } \\
\text { fabricação dos produtos. }\end{array}$ & $\begin{array}{l}\text { Gestores de suprimentos podem } \\
\text { trabalhar e treinar os } \\
\text { fornecedores para melhorarem } \\
\text { sua produção e qualidade. }\end{array}$ \\
\hline Entrega & $\begin{array}{l}\text { Principal função colaboradora } \\
\text { para a capacidade de entrega via } \\
\text { redução de ciclos de entrega. }\end{array}$ & $\begin{array}{l}\text { Evitando gargalos na entrega e } \\
\text { respondendo rapidamente à } \\
\text { demanda via produção enxuta. }\end{array}$ & $\begin{array}{l}\text { A fim de evitar atrasos na } \\
\text { entrega de matéria-prima, } \\
\text { buscar trabalhar em estreita } \\
\text { colaboração } \\
\text { fornecedores. }\end{array}$ \\
\hline $\begin{array}{l}\text { Capacidade } \\
\text { de resposta }\end{array}$ & $\begin{array}{l}\text { Desenvolvendo projetos para } \\
\text { obtenção da adaptabilidade e } \\
\text { flexibilidade de entrega em } \\
\text { eventos inesperados. }\end{array}$ & $\begin{array}{l}\text { Utilizando formas de fabricação, } \\
\text { como montagem modular, que } \\
\text { permitam responder } \\
\text { rapidamente à flutuações e } \\
\text { necessidades imprevistas da } \\
\text { demanda. }\end{array}$ & $\begin{array}{l}\text { Construindo relações estreitas } \\
\text { com os fornecedores para que } \\
\text { estejam dispostos a mudar em } \\
\text { resposta a cenários inesperados } \\
\text { de oferta de suprimentos. }\end{array}$ \\
\hline Inovação & $\begin{array}{l}\text { Oferecendo informações às } \\
\text { equipes de P\&D sobre condições } \\
\text { de transporte e entrega para o } \\
\text { projeto de novos produtos. }\end{array}$ & $\begin{array}{l}\text { Participando dos grupos de P\&D } \\
\text { e trabalhando conjuntamente } \\
\text { com o marketing no projeto de } \\
\text { produtos que possam ser } \\
\text { fabricados mais facilmente. }\end{array}$ & $\begin{array}{l}\text { Fornecendo informações e } \\
\text { especificações de fornecimento } \\
\text { e identificando fornecedores } \\
\text { que possam participar das } \\
\text { equipes de P\&D. }\end{array}$ \\
\hline
\end{tabular}

Fonte: Adaptado de Fawcett e Waller (2013, p. 185).

Portanto, em função da sua natureza inter-relacional, defende-se que a GCS não pode ser restrita ou configurada como uma área funcional específica tal como outras tradicionalmente existentes nas empresas. Os processos-chave de negócio presentes nos modelos da GSCF e SCOR reforçam esses argumentos (Figura 2). De acordo com Lambert (2008), ambos os modelos são similares na necessidade do envolvimento interfuncional e reconhecem que os processos de negócio não substituem a existência das áreas funcionais. 
Figura 2 - Envolvimento funcional nos processos-chave de negócio nos modelos da GSCF e SCOR

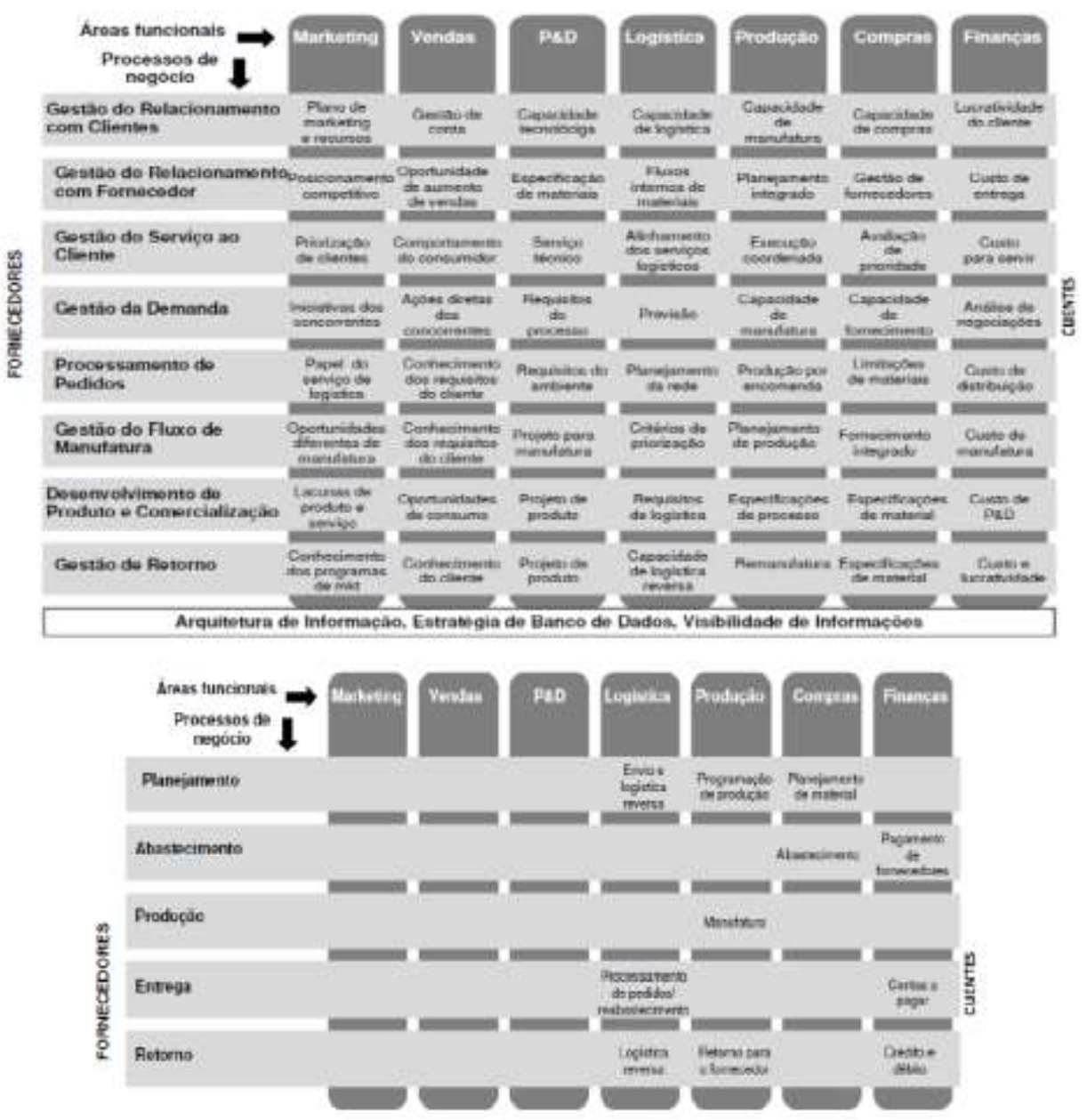

Fonte: Lambert (2008).

Observa-se no modelo da GSCFO que para cada processo-chave de negócio as áreas funcionais têm a prerrogativa de uma atividade específica. Portanto, esses processos somente atingirão seus objetivos se os gestores funcionais tiverem consciência dos inputs que suas áreas promovem para as demais. A necessidade de integração entre áreas funcionais é igualmente evidente no modelo SCOR, bem como a geração de inputs de uma área para outra.

A busca pela efetivação das práticas de GCS igualmente justifica os esforços de integração interna, resultando em diferentes benefícios/melhorias (Droge, Jayaram \& Vickery, 2004; Richey et al., 2009; Barrat \& Barrat, 2011). São alguns exemplos:

- Parceria estratégica com fornecedores: refere-se ao estabelecimento de relacionamentos de longo prazo entre empresas e seus fornecedores, visando alavancar as capacidades estratégicas e operacionais das empresas individualmente e ajudá-las a alcançar os benefícios em curso na cadeia de suprimentos; 
- Desenvolvimento de fornecedores: abrange a realização de visitas por pessoal da empresa compradora à empresa fornecedora, auxílio na obtenção de certificações, oferta de formação e treinamento ao pessoal da empresa fornecedora;

- Relacionamento com os clientes: compreende todo o conjunto de práticas voltadas para a gestão de reclamações de clientes, construção de relacionamentos de longo prazo e melhoria da satisfação;

- Garantia de entrega confiável: refere-se tanto à entrega de produtos e serviços das empresas fornecedores à empresa focal na cadeia de suprimentos como à entrega de produtos e serviços da empresa focal aos consumidores, dependendo dos elos à jusante (transportadores logísticos, distribuidores, revendedores);

- Sincronia entre a oferta e a demanda: o relacionamento com os elos à montante e à jusante na cadeia de suprimentos permite uma melhor previsão da demanda evitando, por exemplo, o afeito chicote;

- Introdução mais rápida de novos produtos: via projetos conjuntos com fornecedores visando a inovação e melhoria de produtos e serviços aos clientes;

- Postergação: definida como a prática de avançar uma ou mais operações ou atividades para elos a jusante na cadeia de suprimentos, possibilitando à empresa focal oferecer alto nível de customização em função da flexibilidade da produção.

Conforme ressaltam Schoenherr e Swink (2012), a integração interna cria capacidade para o processamento de informações que permitem a captação e aplicação de conhecimentos valiosos gerados nas interações externas, traduzindo-os em melhorias operacionais impactantes. Koufteros et al. (2005) trazem um exemplo nesse sentido. Os autores investigaram, entre 244 indústrias, a contribuição da integração interna e externa em projetos de desenvolvimento de novos produtos. Os resultados evidenciaram que pouco os fornecedores poderão contribuir sem antes os próprios profissionais da empresa serem capazes de desenvolver o projeto do produto, inclusive já considerando a perspectiva do cliente. Os autores concluíram que "[...] esforços para integrar fornecedores sem um sistema sensível à integração interna podem ser inúteis" (p.123). Também sob o enfoque da orientação para o cliente, Yunus e Tadisina (2016) observaram empiricamente que as empresas foram levadas a se envolver em colaboração e parceria pela motivação interna, especialmente em direção à satisfação do cliente, e não por pressões externas. Os autores concluem que a integração interna sustenta a Integração da Cadeia de Suprimentos.

Outro enfoque teórico permite defender a integração interna como fundamental para a GCS: o construto da Orientação para a Cadeia de Suprimentos (comumente mencionado no original em inglês - Supply Chain Orientation/SCO). Esse é o assunto abordado na próxima subseção. 


\subsection{Orientação para a GCS}

O cenário até o momento exposto evidencia a importância da integração interna para a GCS. Reforça essa concepção o construto da SCO, entendida como uma filosofia de gestão e definida como "[...] O reconhecimento interno por uma organização das implicações estratégicas e sistêmicas da gestão dos diferentes fluxos dentro de uma cadeia" (MENTZER et al., 2011, p.11 - grifo nosso). De maneira semelhante, Miocevic e Crnjak-Karanovic (2012) afirmam que a SCO suporta as ações de criação de valor como um processo no qual todos os membros da cadeia de suprimentos devem investir seus recursos, habilidades conhecimentos internamente para, posteriormente, interagir os resultados desse esforço por toda a cadeia.

O Quadro 3 apresenta outras definições presentes na literatura, com destaque em grifado para os pontos diretamente relacionados com a discussão deste artigo.

Quadro 3 - Definições de SCO

\begin{tabular}{|c|l|}
\hline $\begin{array}{c}\text { Autores } \\
\begin{array}{c}\text { Stank, Davis e Fugate } \\
(2005, \text { p.32) }\end{array}\end{array}$ & $\begin{array}{l}\text { A adoção da Orientação para a Cadeia de Suprimentos conduz uma empresa a praticar a } \\
\text { Gestão da Cadeia de Suprimentos, caracterizado pela integração dos processos-chave de } \\
\text { negócios. }\end{array}$ \\
\hline $\begin{array}{c}\text { Min, Mentzer e Ladd } \\
\text { A Orientação para a Cadeia de Suprimentos e a Gestão da Cadeia de Suprimentos são } \\
\text { conceitos relacionados, porém diferentes, em que a Orientação para a Cadeia de Suprimentos } \\
\text { é desenvolvida e mantida por uma empresa, enquanto que a Gestão da Cadeia de Suprimentos } \\
\text { (atividades e recursos) é compartilhada nas relações entre os parceiros da cadeia de } \\
\text { suprimentos.(itálico no original) }\end{array}$ \\
$\begin{array}{c}\text { Esper, Defee e Mentzer } \\
\text { (2010, p.163-164) }\end{array}$ & $\begin{array}{l}\text { A Orientação para a Cadeia de Suprimentos é uma função com dupla perspectiva: estratégica } \\
\text { e estrutural. Sua essência está no alinhamento entre ambas as perspectivas a fim de suportar } \\
\text { a Gestão da Cadeia de Suprimentos. Em particular, a Orientação para a Cadeia de Suprimentos } \\
\text { é um conceito empresarial interno, onde as empresas operam em um ambiente de cadeia de } \\
\text { suprimento dentro do mercado global. }\end{array}$ \\
\hline $\begin{array}{c}\text { sengnick-Hall, Lengnick- } \\
\text { Hall e Rigsbee } \\
\text { (2013, p.367) }\end{array}$ & $\begin{array}{l}\text { A Orientação para a Cadeia de Suprimentos significa que a Gestão da Cadeia de Suprimentos } \\
\text { é guiada por uma filosofia abrangente projetada para criar uma estratégia sistêmica, } \\
\text { totalmente integrada e sincronizada entre a oferta de suprimentos e o gerenciamento da }\end{array}$ \\
\hline \begin{tabular}{l} 
demanda. \\
\hline
\end{tabular}
\end{tabular}

Fonte: Elaborado pelas autoras.

Para Esper, Deffe e Mentzer (2010), embora a GCS seja um conceito interorganizacional, compreender a dinâmica interna das empresas como antecedente é um aspecto-chave para os gestores de cadeia de suprimentos. Partindo desse reconhecimento, os autores propõem um modelo conceitual (Figura 3) explicitando como uma empresa deve se organizar para efetivamente adotar essa orientação e usufruir seus benefícios. O modelo é composto por duas dimensões: (1) estratégia para SCO e (2) estrutura para SCO, sendo necessário haver um alinhamento entre ambas. 


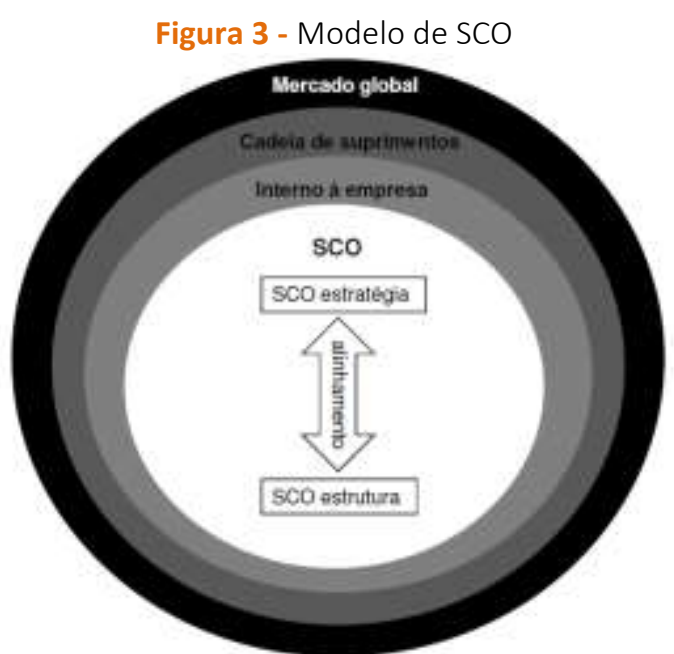

Fonte: Esper et al. (2010, p.164).

A estratégia de SCO significa: (i) visão holística e sistêmica da cadeia de suprimentos, (ii) competição no mercado via cadeia de suprimentos e (iii) ênfase na GCS entre as empresas da cadeia. Essa estratégia é suportada pela estrutura para SCO, cujas categorias estão descritas no Quadro 4.

Quadro 4 - Categorias da estrutura para a SCO

\begin{tabular}{|c|c|}
\hline Configuração organizacional & Recursos humanos \\
\hline $\begin{array}{l}\text { Foca a colaboração interna, a integração e a estrutura } \\
\text { organizacional. Inclui o desenho de estruturas } \\
\text { organizacionais que permitam a colaboração interna entre as } \\
\text { áreas funcionais e sistemas formais de coordenação e } \\
\text { controle das atividades de GCS e suas metas. }\end{array}$ & $\begin{array}{l}\text { Admite que as áreas funcionais com atividades voltadas à } \\
\text { Gestão da Cadeia de Suprimentos somente terão bom } \\
\text { desempenho se houver devido suporte das competências } \\
\text { humanas. Para tanto, indicam: (i) contratação de pessoal } \\
\text { com habilidades-chave acerca da GCS, (ii) foco na } \\
\text { satisfação do funcionário para melhor desenvolvimento de } \\
\text { suas atividades, (iii) inserção de figuras de liderança e de } \\
\text { estruturas que facilitem o aprendizado, a atuação de } \\
\text { equipes multifuncionais e a realização de treinamentos. }\end{array}$ \\
\hline Tecnologia da informação & Mensuração organizacional \\
\hline $\begin{array}{l}\text { Desenvolvimento de competências de tecnologia da } \\
\text { informação que facilitem a integração interna e a troca de } \\
\text { informações entre as empresas da cadeia de suprimentos. }\end{array}$ & $\begin{array}{l}\text { Adoção de medidas de diagnóstico e monitoramento que } \\
\text { facilitem as perspectivas de alinhamento, aprendizagem, } \\
\text { inovação e integração da cadeia de suprimentos. }\end{array}$ \\
\hline
\end{tabular}

Fonte: Adaptado de Esper et al. (2010, p.165-171).

Em suma, a SCO é a concretização da GCS enquanto uma filosofia de gestão no contexto interno de cada empresa componente de uma cadeia de suprimentos. No entanto, apesar de o foco ser a dimensão interna de uma empresa, o propósito final é a expansão da sua capacitação intraorganizacional para o relacionamento com os demais membros externos da cadeia de suprimentos. 
3 Procedimentos metodológicos

Para atender ao objetivo proposto neste artigo, além da revisão da literatura até o momento apresentada, foi realizada uma pesquisa de campo, de abordagem qualitativa e utilizando como método de pesquisa estudo de casos múltiplos. Em verdade, há um crescente chamado pelo desenvolvimento de pesquisas qualitativas no campo da GCS que se utilizem do método de estudo de caso (Seuring, 2005).

A revisão da literatura iniciou-se pelo estudo do tema "Gestão da Cadeia de Suprimentos", em livros e artigos de renomados autores nacionais e internacionais, tais como Mentzer et al. (2001), Chen e Paulraj (2004), Pires (2010), entre outros citados ao longo da fundamentação teórica (seção 2). Já no processo de busca em periódicos internacionais foram consultadas, respectivamente, as bases de dados Scopus e Web of Science. Mais especificamente, buscou-se trabalhos com discussões referentes à Integração da Cadeia de Suprimentos, com ênfase na integração interna. Mais que permitir a contextualização da pesquisa e sua fundamentação teórica, os trabalhos selecionados permitiram a identificação de pontos importantes a serem levantados na pesquisa de campo. Os mesmos serão apresentados ainda nesta seção, quando da descrição do roteiro de entrevista.

Para a etapa da pesquisa de campo, foram investigadas seis empresas nacionais representativas nos seus mercados de atuação (nacional e internacional), de diferentes setores industriais e selecionadas por conveniência. Além do intuito de obter o máximo de variações no conteúdo dos dados coletados, outra justificativa para a não limitação em um setor específico está no próprio grau de maturidade do tema em análise, estando ainda em fase exploratória. O principal parâmetro para a composição da amostra foi a escolha de empresas que tivessem a designação do cargo de "Gestor da Cadeia de Suprimentos" ou função equivalente (entende-se por "função equivalente" o caso de empresas que designam a função de gerenciar a cadeia de suprimentos para gestor de alguma outra área funcional, uma vez que poucas possuem uma área específica ou cargo específico de GCS). Consequentemente, seriam empresas que, de alguma forma, realizam a GCS: no caso, outro parâmetro fundamental.

A coleta de dados ocorreu entre os meses de Outubro de 2015 e Fevereiro de 2016, tendo sido utilizados três instrumentos: (1) entrevistas semi-estruturadas, com o apoio de um roteiro de entrevista, (2) análise documental e (3) observação direta. O roteiro de entrevista foi composto de duas partes: (i) caracterização geral da empresa e (ii) caracterização da GCS e da integração interna para a GCS, ambos destinados ao gestor de cadeia de suprimentos ou função equivalente. As questões foram formuladas com base na revisão da literatura realizada e também objetivando a interação entre os tópicos teóricos. A formulação buscou também privilegiar a narrativa livre da pessoa entrevistada, tentando reduzir a interferência da pesquisadora.O Quadro 5 apresenta as questões aplicadas e sua associação com o referencial teórico. 


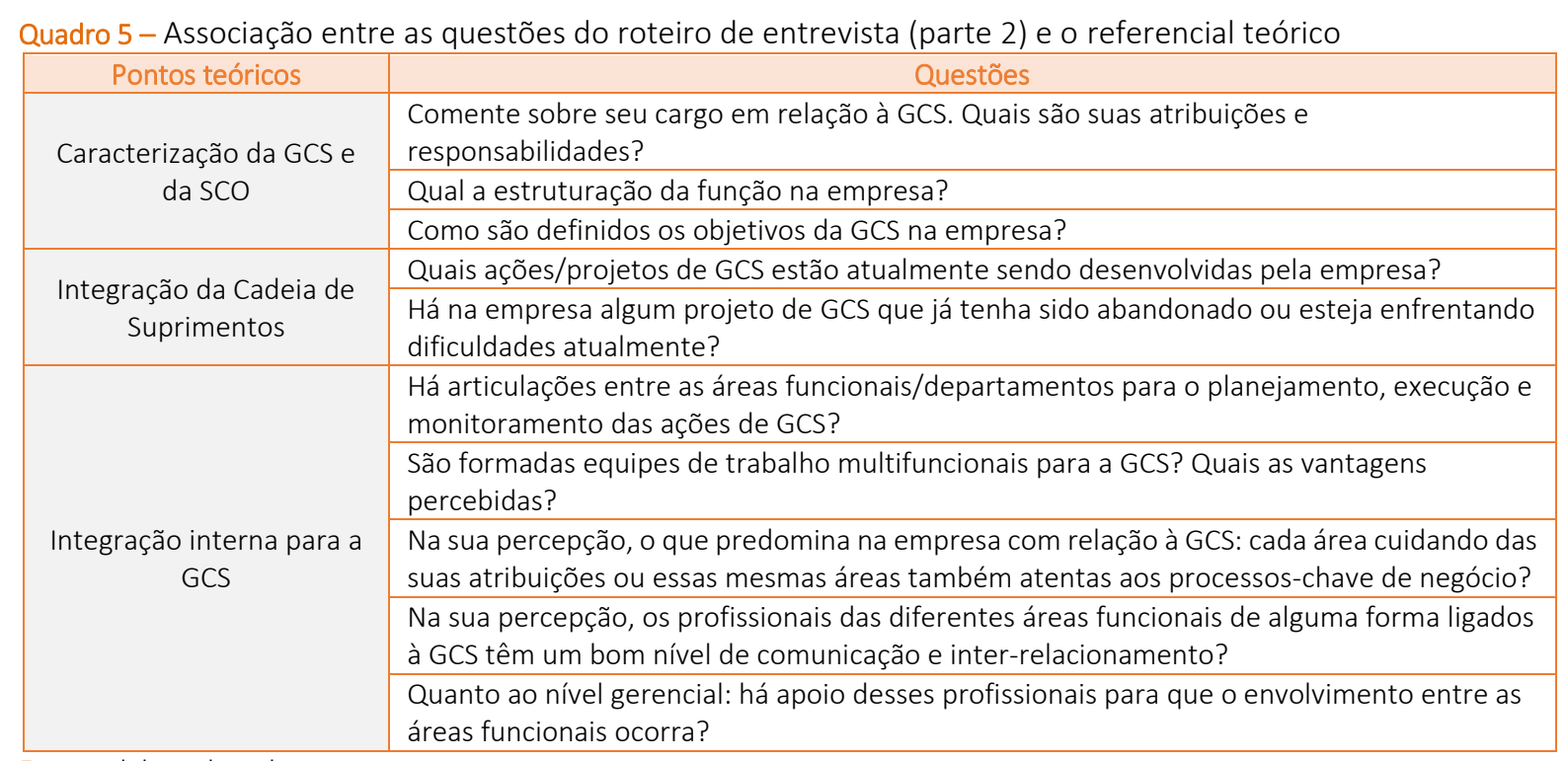

Fonte: Elaborado pelas autoras.

Todas as nove entrevistas em profundidade foram realizadas in loco, fato que favoreceu a observação direta e a captação de informações relevantes para a pesquisa além daquelas previstas nos roteiros de entrevista. Por exemplo, em cinco delas foi possível observar o layout e a dinâmica das áreas administrativas. As entrevistas foram gravadas em áudio, somando aproximadamente treze horas de gravação. Já a análise documental se deu pelo acesso a documentos internos, disponibilizados durante as entrevistas e visitas às instalações, a softwares da área de GCS e a informações disponibilizadas na internet.

As entrevistas e as anotações de campo foram transcritas de maneira literal e posteriormente analisadas e codificadas com o uso da técnica de Análise de Conteúdo, que Bardin (2011, p.48) conceitua como sendo um "[...] conjunto de técnicas de análise das comunicações visando obter, por procedimentos sistemáticos e objetivos de descrição do conteúdo das mensagens indicadores (quantitativos ou não) que permitam a inferência de conhecimentos relativos às condições de produção/recepção (variáveis inferidas) destas mensagens". Com relação à construção das categorias, codificação e referências, foram classificadas duas categorias: (1) Caracterização da GCS na empresa e (2) Integração interna para a GCS. A primeira resultou em 7 sub-categorias, totalizando 128 referências. Já a segunda resultou em 6 sub-categorias, totalizando 187 referências. Entende-se por "referências" a quantidade de trechos das falas dos entrevistados relacionados às sub-categorias. Como apoio nessa fase, utilizou-se o software NVivo11.

O Quadro 6 caracteriza as empresas investigadas, especifica os profissionais entrevistados em cada uma delas e seus respectivos códigos de referência oriundos da Análise de Conteúdo. Os mesmos serão utilizados na apresentação dos resultados. 
Quadro 6 - Empresas investigadas, profissionais entrevistados e códigos de referência

\begin{tabular}{|c|c|c|c|c|}
\hline Caso & Setor de atuação & $\begin{array}{l}\text { Número de } \\
\text { funcionários }\end{array}$ & Profissionais entrevistados & Códigos \\
\hline Empresa 1 & $\begin{array}{l}\text { Usina de açúcar e } \\
\text { álcool }\end{array}$ & 3.500 & Gerente de Supply Chain & PGCS1 \\
\hline \multirow{2}{*}{ Empresa 2} & \multirow{2}{*}{$\begin{array}{l}\text { Frigorífico } \\
\text { (carne bovina) }\end{array}$} & \multirow{2}{*}{2.500} & Gerente Executivo de Originação & PGCS2 \\
\hline & & & Diretor de Processos, TI e Compliance & DPTC2 \\
\hline \multirow[t]{2}{*}{ Empresa 3} & \multirow[t]{2}{*}{$\begin{array}{l}\text { Alimentos } \\
\text { (confeitos e snacks) }\end{array}$} & \multirow[t]{2}{*}{2.000} & $\begin{array}{l}\text { Gerente de Planejamento de Demanda, } \\
\text { Vendas e Operações (PDVO) }\end{array}$ & PGCS3 \\
\hline & & & Diretor de Supply Chain & DSC3 \\
\hline Empresa 4 & Máquinas agrícolas & 1.280 & Gerente de PPCP & PGCS4 \\
\hline Empresa 5 & $\begin{array}{l}\text { Embalagens } \\
\text { plásticas }\end{array}$ & 350 & Gerente de Supply Chain & PGCS5 \\
\hline \multirow{2}{*}{ Empresa 6} & \multirow{2}{*}{ Eletroeletrônico } & \multirow{2}{*}{300} & Gerente de Supply Chain & PGCS6 \\
\hline & & & Diretor Geral & DG6 \\
\hline
\end{tabular}

Fonte: Elaborado pelas autoras.

Nota: "P" de Profissional + sigla da área ou cargo + número referência ao caso.

4 Apresentação e análise dos resultados intercasos

Primeiramente, é importante ressaltar que análise dos resultados foi efetuada seguindo a proposta de Yin (2005) para estudo de casos múltiplos: uma análise intracasos preliminar, seguida de uma análise intercasos. Os casos foram analisados considerando a técnica pattern-matching, permitindo uma comparação entre os resultados teóricos e os resultados reais, ou seja, uma comparação entre o padrão predito e o empírico. Privilegiando uma apresentação mais objetiva e sistematizada, optou-se neste artigo pela apresentação da análise dos resultados intercasos. Destaca-se ainda que a análise intercasos não objetivou realizar uma análise comparativa entre os casos, mas sim levantar as contribuições da integração interna para a capacitação da empresa na sua atuação externa com os demais elos da cadeia produtiva.

Embora se defenda que a GCS não deve ser restrita ou configurada como uma área funcional específica constatou-se que três das empresas investigadas adotam a configuração da função na forma departamental. No entanto, a dinâmica para o planejamento e execução das atividades de cadeia de suprimentos demonstrou-se predominantemente interfuncional. Pela análise dos organogramas da área de Supply Chain dessas empresas (Quadro 7) é possível observar que, ao inserir atividades advindas de diferentes áreas funcionais, não se utilizou o princípio de especialização funcional para a configuração da função. Conforme expressou o Gerente de Supply Chain da Empresa 5:

Era até uma busca já desde o princípio a gente conseguir formatar uma área de Supply com todas as operações afins. (...) a gente veio formatando a equipe e a melhor divisão dos processos e procedimentos internos pra que a gente conseguisse gerar uma amarração ideal das três áreas. (PGCS5). 
Quadro 7 - Representação da GCS nas empresas investigadas

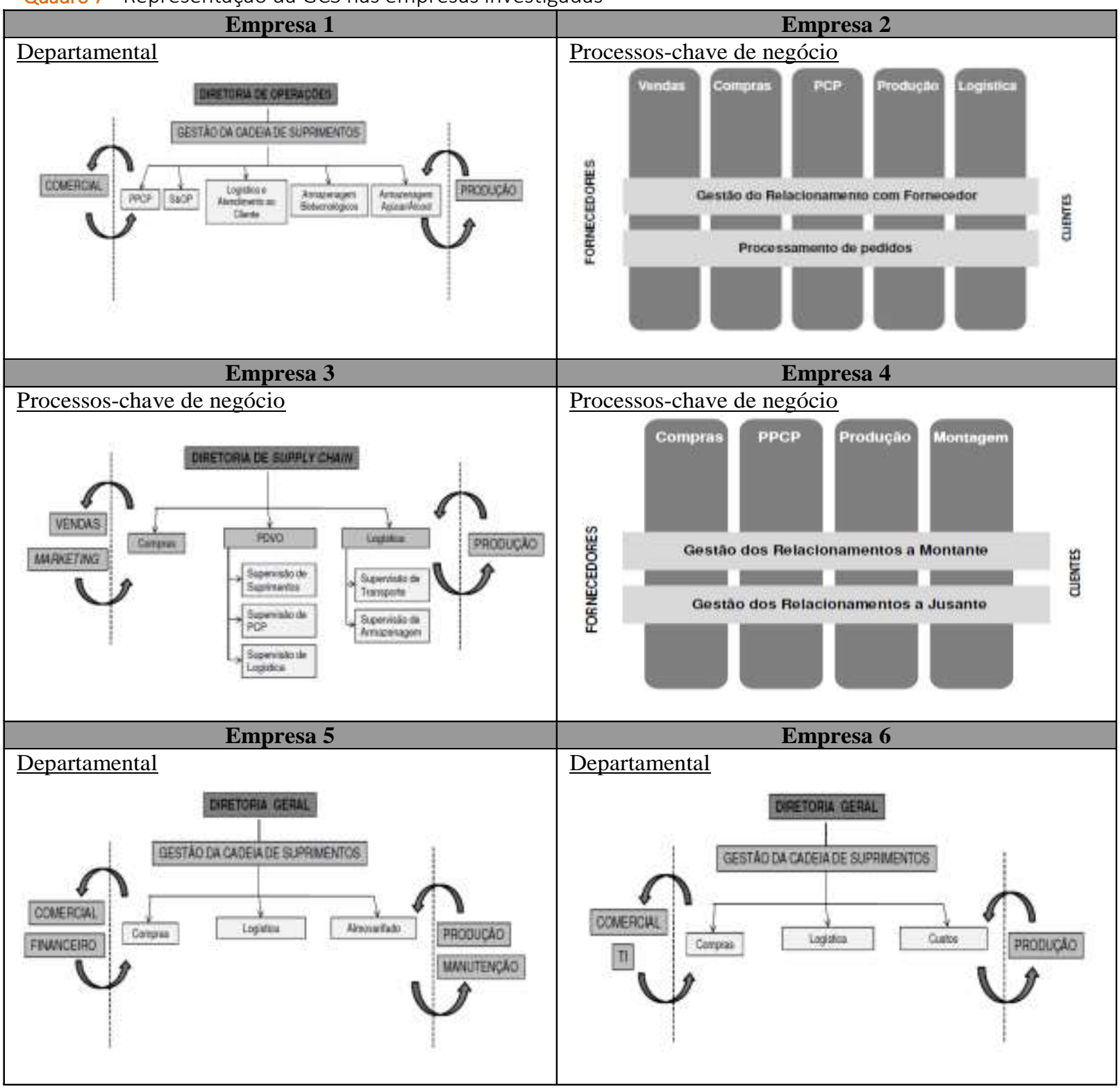

Fonte: Elaborado pelas autoras.

Já nas Empresas 2, 3 e 4 tem-se a gestão dos processos-chave de negócio que, por definição, exigem a interfuncionalidade para a sua execução (Chopra \& Meindl, 2012). As principais áreas funcionais envolvidas com a GCS entre as seis empresas investigadas são: Compras, Logística, Produção, Vendas, Marketing, Financeiro, Planejamento e Controle da Produção/PCP e Tecnologia da Informação/TI. Tais áreas são de fato indicadas nas definições e modelos de cadeia de suprimentos (Mentzer et al., 2001; Lambert, 2008). Foram ainda observadas a interação com as funções Armazenamento, Montagem e Manutenção.

A integração funcional comporta a presença de ações nas dimensões interação e colaboração. Nas seis empresas investigadas constatou-se a presença de ações em ambas as dimensões, sintetizadas no Quadro 8. 
Quadro 8 - Síntese da caracterização das dimensões interação e colaboração

\begin{tabular}{|c|c|c|c|}
\hline & Natureza & Recursos utilizados & Benefícios \\
\hline 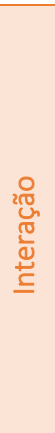 & Formal & $\begin{array}{l}\text { - reuniões interfuncionais, com a participação de } \\
\text { profissionais das diferentes áreas funcionais } \\
\text { envolvidas com a GCS } \\
\text { - reuniões entre os profissionais da própria área de } \\
\text { Supply Chain: planejamento de metas, divulgação de } \\
\text { resultados } \\
\text { - conferências e convenções entre profissionais } \\
\text { envolvidos com a GCS das diferentes unidades } \\
\text { produtivas da empresa } \\
\text { - formação de comitê de Qualidade e Atendimento } \\
\text { ao Cliente }\end{array}$ & $\begin{array}{l}\text { - melhor planejamento e acompanhamento } \\
\text { das ações de GCS } \\
\text { - geração de responsabilidade conjunta } \\
\text { entre os profissionais das diferentes áreas } \\
\text { funcionais envolvidas com a GCS } \\
\text { - geração da visão sistêmica do negócio }\end{array}$ \\
\hline 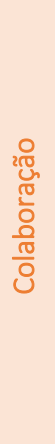 & Informal & $\begin{array}{l}\text { - compartilhamento de informação e conhecimento } \\
\text { na rotina do desenvolvimento das atividades } \\
\text { programadas nas reuniões formais } \\
\text { - ações voluntárias para a resolução de problemas } \\
\text { fora dos momentos formais de discussão } \\
\text { - comunicação entre os profissionais, com base na } \\
\text { confiança e no comprometimento } \\
\text { - layouts nas áreas administrativas que geram } \\
\text { proximidade e facilitam a comunicação entre os } \\
\text { profissionais das diferentes áreas funcionais } \\
\text { envolvidas com a GCS }\end{array}$ & $\begin{array}{l}\text { - tomada de decisão, atualização das } \\
\text { informações e resolução de problemas } \\
\text { conduzidos de maneira mais rápida } \\
\text { - a colaboração ajuda a concretizar os } \\
\text { planos formais traçados nas ações de } \\
\text { interação } \\
\text { - por meio da colaboração as barreiras à } \\
\text { integração interna são mais facilmente } \\
\text { suplantadas } \\
\text { - geração de maior envolvimento e } \\
\text { comprometimento dos profissionais }\end{array}$ \\
\hline
\end{tabular}

Fonte: Elaborado pelas autoras.

A dimensão interação demonstrou-se caracterizada por ações de natureza formal, por meio especialmente de reuniões interfuncionais de planejamento das estratégias de cadeia de suprimentos e acompanhamento das atividades realizadas, dos resultados alcançados e das principais dificuldades enfrentadas. É o caso, por exemplo, das reuniões mensais de S\&OP realizadas pelas empresas 1, 2, 3 e 4 e das ações relacionadas à um projeto de supply chain envolvendo fornecedores e revendedores da Empresa 4.

Já a dimensão colaboração demonstrou-se caracterizada por ações de natureza informal, por meio especialmente do compartilhamento de informações e conhecimento entre os profissionais envolvidos com a GCS. Nas Empresas 5 e 6, tal dimensão demonstrou-se predominante em relação à dimensão interação, ou seja, as empresas valorizam mais a informalidade nas interações entre as áreas funcionais em detrimento da formalidade. De acordo Kahn e Mentzer (1996), em um nível mais avançado, há a presença de ambas as dimensões, devendo ser consideradas pelas empresas de maneira conjunta e complementar. Exceto na Empresa 3, em todas as demais observou-se que as ações de colaboração complementam as ações formais de interação. Conforme expressou o Gerente de Originação da Empresa 2: "Coisa simples mas que faz uma diferença. Você estar em contato, você tá ali sentado do lado, vendo o que tá acontecendo. Além de ter as reuniões formais, os relatórios, os indicadores, isso o que todos nós acompanhamos" (PGCS2).

O papel da integração interna para a efetivação das práticas e projetos de GCS vem obtendo destaque na literatura especializada, cujos efeitos trazem benefícios tanto para a execução das atividades de cadeia de suprimentos internamente à empresa, como externamente na integração com fornecedores e clientes (Jin et al., 2013; Horn et al., 2014). Na totalidade dos casos investigados contatou-se a presença dessa compreensão. Conforme expressou o Gerente de Supply Chain da Empresa 1: "No final a cadeia inteira ganha. E aí, 
consequentemente, na parte de produto acabado e depois na entrega isso aí também é refletido no nosso cliente final. É confiabilidade que gera fidelização" (PGCS1). Outro exemplo é fala do Diretor de Supply Chain da Empresa 3: "O supply, é uma área de apoio... Então, o que me interessa de eu ter um indicador interno perfeito se eu não atendo bem o cliente ou o contrário, meu foco comercial maravilhoso, mas aqui dentro eu deixo a desejar com a produção, com isso e com aquilo (DSC3)". Tail constatação confirma as discussões mais recentes da literatura especializada nesse sentido (Ralston et al., 2015; Zhao \& Wang, 2015).

No Quadro 9 estão elencados os benefícios e melhorias para a execução das atividades de GCS e os reflexos gerados na integração externa com fornecedores e clientes advindos dos esforços de integração interna constatados nas empresas investigadas.

Quadro 9 - Benefícios/melhorias da integração interna para a GCS nas empresas investigadas

\begin{tabular}{|c|c|c|}
\hline $\begin{array}{l}\text { Benefícios } \\
\text { Melhorias }\end{array}$ & Empresas & os entrel \\
\hline $\begin{array}{l}\text { Integração de } \\
\text { processos }\end{array}$ & $\begin{array}{l}1,2,3 \\
4 \text { e } 5\end{array}$ & $\begin{array}{l}\text { E é aquela história: se tiver o acerto, todo mundo acertou. Se tiver o erro, todo mundo } \\
\text { errou. Então não tem aquela cobrança: se diminuiu um pouco aquela pressão sobre } \\
\text { algumas áreas específicas. Então isso foi muito bom, foi muito positivo. Melhorou a } \\
\text { integração entre as áreas. (DSC3) }\end{array}$ \\
\hline $\begin{array}{l}\text { Aumento da sinergia e } \\
\text { redução de erros }\end{array}$ & $1,3,5$ e 6 & $\begin{array}{l}\text { [...] aí aqui coordena junto com logística e fala assim: "Oh, vocês precisam entregar isso" } \\
\text { bom, tem a parte dos clientes e tem a parte de transferência para nossos armazéns nos } \\
\text { Estados Unidos e Europa. E aí essa turma aqui tem uma conversa muito grande com a } \\
\text { parte de armazenagem por causa das janelas de carregamento. Então, eu sei qual é a } \\
\text { minha carteira, o que eu vou produzir, o que eu preciso mandar no curto prazo. (PGCS1) }\end{array}$ \\
\hline $\begin{array}{l}\text { Melhoria dos } \\
\text { resultados funcionais }\end{array}$ & $2,4,5$ e 6 & $\begin{array}{l}\text { Hoje a minha logística, por exemplo, tem um processo de expedição muito amarrado. } \\
\text { Então assim, dificilmente hoje a gente tem atrasos ocasionados pela logística. (PGCS5) }\end{array}$ \\
\hline $\begin{array}{l}\text { Decisões mais } \\
\text { acertadas }\end{array}$ & $1,2,3$ e 4 & $\begin{array}{l}\text { Ele é longo porque teve toda uma estruturação de modelo de como é que a gente ia } \\
\text { operar internamente, construção do modelo a varias mãos, e essa é a proposta que a X } \\
\text { quer trabalhar como modelo de operação. Aí sim começamos a ir aos clientes e } \\
\text { começamos a ir aos fornecedores. (PGCS4) }\end{array}$ \\
\hline $\begin{array}{l}\text { Melhoria na } \\
\text { comunicação }\end{array}$ & 1,4 e 6 & $\begin{array}{l}\text { Alguém falhou ali na cadeia e a informação corre rápido. "oh, faltou material... ah, a } \\
\text { máquina tal tá quebrada" então, eles tem esse... tem acesso à informação também, não } \\
\text { é nada tão fechado assim. (PGCS6) }\end{array}$ \\
\hline $\begin{array}{l}\text { Benefícios } \\
\text { Melhorias }\end{array}$ & Empresas & Afirmações dos entrevistados \\
\hline $\begin{array}{l}\text { Parceria estratégica } \\
\text { com fornecedores }\end{array}$ & Todas & $\begin{array}{l}\text { (...) você tendo um planejamento mais sólido, mais robusto, mais confiável, com menos } \\
\text { alterações isso reflete para fora, tanto na parte de vendas como na parte....vendas já } \\
\text { sabe o que ele vai receber para poder comercializar, o fornecedor já sabe o que tem que } \\
\text { produzir para poder me entregar então você ganha uma estabilidade na cadeia (PGCS3). }\end{array}$ \\
\hline $\begin{array}{l}\text { Garantia de entrega } \\
\text { confiável }\end{array}$ & $1,2,3$ e 6 & $\begin{array}{l}\text { (...) pra unidade X a melhor carteira é fazer Chile, Irã, Europa. Então vamos fazer tanto } \\
\text { de Ira, tanto de Chile e tanto de Europa. "Oh comercial, você vai ter que vender tanto } \\
\text { pra Europa, tanto pro Chile e tanto pro Irã. Compra de gado, pra atender esse mix ótimo } \\
\text { aqui você vai ter que comprar boi assim e assim. Oh PCP, organiza a distribuição dessa } \\
\text { carteira toda, organiza as saídas..." (PGCS2). }\end{array}$ \\
\hline $\begin{array}{l}\text { Relacionamento com } \\
\text { clientes }\end{array}$ & 1 e 2 & $\begin{array}{l}\text { Você tinha um backlog enorme e daí os clientes "Tudo bem, eu não comprei esse mês, } \\
\text { então não vou comprar o mês que vem o dobro. Se você não tiver esse mês, eu vou } \\
\text { comprar dum outro fornecedor porque eu preciso rodar a minha planta". [...] O nosso } \\
\text { backlog hoje é praticamente inexistente, os clientes tem falado super bem... então, todo } \\
\text { mundo tem sentido isso. (PGCS1) }\end{array}$ \\
\hline $\begin{array}{l}\text { Sincronia entre a } \\
\text { oferta e a demanda }\end{array}$ & 4 e 5 & $\begin{array}{l}\text { Então a gente tem uma estruturação não só dos nossos parceiros de transporte, mas da } \\
\text { nossa operação de expedição de uma maneira que não permita que o material acabado } \\
\text { fique parado no nosso estoque. Salvo se eu tiver alguma situação de data, uma situação } \\
\text { do cliente, alguma situação, uma variável que eu não consiga controlar, esse material vai } \\
\text { sair. (PGCS5) }\end{array}$ \\
\hline
\end{tabular}

Fonte: Elaborado pelas autoras.

Uma interessante constatação obtida, emergindo como um código a posteriori durante a codificação das entrevistas, diz respeito à atuação do gestor de Cadeia de Suprimentos como um agente de integração, ou seja, como o profissional responsável pela coordenação dos esforços advindos das diferentes áreas funcionais 
envolvidas com a GCS. Nas Empresas 1, 5 e 6 tal atuação é realizada pelo próprio Gerente de Supply Chain e nas demais pelos gerentes da área funcional com maior representatividade nos processos-chave de negócio. Com efeito, a principal contribuição observada é o apoio na efetivação da integração interna, especialmente no que tange à busca pela superação das barreiras, como por exemplo, dificuldade de comunicação.

5 Considerações finais

A Integração da Cadeia de Suprimentos é reconhecida como essencial para melhorar o desempenho das empresas e a competitividade da cadeia de suprimentos como um todo. Consequentemente, as empresas têm se conscientizado de que a integração é uma questão estratégica fundamental. O objetivo deste artigo foi investigar a integração interna para a execução das atividades e processos de negócio da GCS e os efeitos gerados na Integração da Cadeia de Suprimentos.

Nas seis empresas investigadas constatou-se o fomento gerencial por meio de planos formais, bem como de comportamentos interativos e colaborativos entre os pares de trabalho, visando a integração interna entre as áreas e/ou atividades funcionais diretamente envolvidas com a GCS. A configuração interfuncional para a GCS e a presença de ações de integração interfuncional nas dimensões "interação" e "colaboração" comprovam essa conscientização. Destaca-se ainda a constatação da atuação dos Gerentes de Supply Chain (ou função equivalente) como um agente de integração.

Portanto, mesmo que inconscientemente por parte dos gestores entrevistados, observa-se que tais empresas possuem uma Orientação para a Cadeia de Suprimentos (SCO) não somente pelo reconhecimento interno das implicações sistêmicas da gestão dos diferentes fluxos dentro de uma cadeia, mas também pela presença das categorias "configuração organizacional" e "recursos humanos" previstos no modelo de SCO (Esper et al., 2010).

Seja visando uma melhor integração à montante da cadeia de suprimentos (Empresas 2, 5 e 6), à jusante (Empresas 1 e 3) ou ambos (Empresa 4), foram observados esforços gerenciais em busca da obtenção e/ou melhoria da integração interna para os propósitos específicos da GCS, bem como a relação direta desses esforços de integração interna na melhoria da integração externa. Tais resultados sugerem que a busca pela integração interna e externa geram efeitos sinérgicos nas ações de Integração da Cadeia de Suprimentos, aumento suas chances de sucesso e, consequentemente, o desempenho das empresas na cadeia de suprimentos.

Em verdade, a motivação para implantar processos de negócio para a GCS é expandir a integração das áreas funcionais de uma empresa focal com as áreas funcionais de outras empresas à montante e à jusante da cadeia de suprimentos, estágio esse que configura a integração externa. No entanto, a atuação interna dessa mesma empresa focal pode inviabilizar a efetivação da integração externa, por exemplo, se a capacidade de manufatura e a capacidade de logística não tiverem sido consultadas antes do fechamento do prazo para a entrega de um pedido a um revendedor, por sua vez atingindo o consumidor final. Porém, a complexidade de implantação e execução dos processos de negócio deve ser reconhecida. O paradigma de "processo" implica examinar as empresas com base nos processos que desempenham ao invés de departamentos funcionais divididos e isolados. 
Os resultados desta pesquisa oferecem uma importante contribuição para o campo de gestão de operações, uma vez que a maior parte das pesquisas sobre Integração da Cadeia de Suprimentos enfatiza somente as práticas referentes à integração externa entre os elos à montante e à jusante (Horn et al., 2014). Em vista disso, é normal a maior associação da concepção de GCS como sendo somente o gerenciamento entre os elos externos, negligenciando assim o papel da integração interna entre as áreas funcionais.

A conscientização sobre a relação entre o nível e a qualidade da integração interna entre as áreas funcionais e o sucesso das iniciativas de relacionamentos externos entre os membros da cadeia de suprimentos pode modificar a forma como os gestores estão planejando e gerenciando os processos-chave de negócio. Sendo assim, gestores e pesquisadores não devem tratar a integração interna e a integração externa para a GCS como independentes, mas sim devem usar uma abordagem holística para gerenciar as ações de Integração da Cadeia de Suprimentos.

Ressalta-se que os resultados obtidos nesta pesquisa não podem ser generalizados, sendo essa uma limitação implícita ao método de pesquisa utilizado. Deste modo, a abrangência de qualquer definição ou experiência mencionada deve ser estudada de maneira mais ampla. Como sugestão de trabalhos futuros, visando atenuar essa limitação, sugere-se a utilização de métodos quantitativos ou pesquisas com abordagem triangular, consideradas mais robustas por utilizarem diferentes fontes de informação e formas de análises (Barrat \& Barrat, 2011). Indicam-se ainda outras duas sugestões de pesquisa futura a partir dos resultados desta: (i) o papel do fator humano na Integração da Cadeia de Suprimentos, especialmente considerando a constatação empírica da predominância da dimensão "colaboração" em detrimento da dimensão "interação", (ii) o papel do gestor de cadeia de suprimentos tanto como um agente de integração como um gestor de pessoas e (iii) pesquisar que abordem o papel da integração interna e externa em ações específicas de Integração da Cadeia de Suprimentos tais como desenvolvimento de novos produtos, abertura de novos canais de distribuição, adoção de práticas de gestão da qualidade, entre outras.

\section{Referências}

Bardin, L. (2011). Análise de conteúdo. Lisboa: Edições 70, 2011.

Barki, H. A., \& Pinsonneault, A. (2005). A model of organizational integration, implementation effort, and performance. Organization Science, 16(2), 165-179.

Barrat, M., \& Barrat, R. (2011). Exploring internal and external supply chain linkages: evidence from the field. Journal of Operations Management, 29, 514-528.

Basnet, C. (2013). The measurement of internal supply chain integration. Management Research Review, 36(2), 153-172.

Braganza, A. Enterprise integration: creating competitive capabilities. (2002). Integrated Manufacturing Systems, 13(8), 562-572.

Chen, I. J., \& Paulraj, A. (2004). Understanding supply chain management: critical research and a theoretical framework. International Journal of Production Research, 42(1), 131-163. 
Chopra, S., \& Meindl, P. (2012). Supply chain management: strategy, planning and operation. 5 ed. Prentice Hall PTR, UpperSaddle River.

Droge, C.; Jayaram, J.; Vickery, S. K (2004). The effects of internal versus external integration practices on timebased performance and overall firm performance. Journal of Operations Management, 22, 557-573.

Esper, T. L., Defee, C. C., \& Mentzer, J. T. (2010). A framework of supply chain orientation. The International Journal of Logistics Management, 21(2), 161-179.

Fawcett, S. E., \& Waller, M. A. (2013). Considering supply chain management's professional identity: the beautiful discipline (or, "we don't cure cancer, but we do make a big difference"). Journal of Business Logistics, 34(3), 183-188.

Fawcett, S. E., Mccarter, M. W., Fawcett, A. M., Webb, G. S., \& Magnan, G. M. (2015). Why supply chain collaboration fails: the socio-structural view of resistance to relational strategies. Supply Chain Management: An International Journal, 20(6), 648-663.

Flynn, B. B.; Huo, B.; Zhao, X. (2010). The impact of supply chain integration on performance: a contingency and configuration approach. Journal of Operations Management, 28, 58-71.

Horn, P., Scheffler, P., \& Schiele, H. (2014). Internal integration as a pre-condition for external integration in global sourcing: a social capital perspective. International Journal of Production Economics, 153, 54-55.

Jin, Y. H., Fawcett, A. M., \& Fawcett, S. E. (2013). Awareness is not enough: commitment and performance implications of supply chain integration. International Journal of Physical, Distribution \& Logistics Management, 43(3), 205-230.

Kahn, K, B., \& Mentzer, J. T. (1996). Logistics and interdepartmental integration. International Journal of Physical Distribution \& Logistics Management, 26(8), 6-14.

Kamal, M. M., \& Irani, Z. (2014) Analysing supply chain integration through a systematic literature review: a normative perspective. Supply Chain Management: An International Journal, 19(5/6), 523-557.

Kotzab, H., Teller, C., Grant, D. B., \& Sparks, L. (2011). Antecedents for the adoption and execution of supply chain management. Supply Chain Management: An International Journal, 16(4), 231-245.

Koufteros, X., Vonderembse, M., \& Jayaram, J. (2005). Internal and external integration for product development: the contingency effects of uncertainty, equivocality, and platform strategy. Decision Sciences, 36(1), 97-133.

Lambert, D. M. (2008). Supply chain management. In: Lambert, D. M. Supply chain management: processes, partnerships, performance. 3 ed. Florida: Supply Chain Management Institute, 1-24.

Lengnick-Hall, M. L.; Lengnick-Hall, C. A.; Rigsbee, C. M. (2013). Strategic human resource management and supply chain orientation. Human Resource Management Review, 23, 366-377.

Mentzer, J. T., Witt, W., Keebler, J. S., Min, S., Nix, N. W., Smith, C. D., \& Zacharia, Z. G. (2001). Defining supply chain management. Journal of Business Logistics, 22(2), 1-25.

Min, S.; Mentzer, J. T.; Ladd, R. T. (2007). A market orientation in supply chain management. Journal of the Academy of Marketing Science, 35(4), 507-522.

Miocevic, D., \& Crnjak-Karanovic, B. (2012). The mediating role of key supplier relationship management practices on supply chain orientation: the organizational buying effectiveness link. Industrial Marketing Management, 41, 115-124. 
Pires, S. R. I. (2010). Gestão da cadeia de suprimentos: conceitos, estratégias, práticas e casos. 2 ed. São Paulo: Atlas.

Ralston, P. M., Blackhurst, J., Cantor, D. E., \& Crum, M. R. A. (2015). structure-conduct-performance perspective of how strategic supply chain integration affects firm performance. Journal of Supply Chain Management, 51(2), 47-64.

Richey, R. G., Chen, H., Upreti, R., Fawcett, S. E., \& Adams, F. G. (2009). The moderating role of barriers on the relationship between drivers to supply chain integration and firm performance. International Journal of Physical Distribution and Logistics Management, 39(10), 826-840.

Schoenherr, T., \& Swink, M. (2012). Revisiting the arcs of integration: cross-validations and extensions. Journal of Operations Management, 30, 99-115.

Seuring, S. (2005). Case study research in supply chains: an outline and three examples. In: Kotzab, H., Seuring, S., Muller, M., \& Reiner, G. (Ed.) Research methodologies in supply chain management. New York: PhysicaVerlag, 235-250.

Stank, T. P.; Davis, B. R.; Fugate, B. S. (2005). A strategic framework for supply chain oriented logistics, Journal of Business Logistics, 26(2), 27-46.

Wong, C. W. Y., Wong, C. Y., \& Boon-Itt, S. (2013). The combined effects of internal and external supply chain integration on product innovation. International Journal of Production Economics, 146, 566-574.

Yin, R. K. (2005). Estudo de caso: planejamento e métodos. 3 ed. Porto Alegre: Bookman.

Yunus, E. N., \& Tadisina, S. K. (2016). Drivers of supply chain integration and the role of organizational culture: empirical evidence from Indonesia. Business Process Management Journal, 22(1), 89-115.

Zhao, G., Feng, T., \& Wang, D. (2015). Is more supply chain integration always beneficial to financial performance? Industrial Marketing Management, 45, 162-172.

Recebido em: 22 fev. 2018 / Aprovado em: 01 abr. 2019

Para referenciar este texto

Siqueira, A. de A., \& Alcântara, R. L. C. (2020). Integração interna para a Integração da Cadeia de Suprimentos: um estudo multicaso. Exacta, 18(2), 368-386. https://doi.org/10.5585/ExactaEP.v18n2.8386. 